\title{
Heave Compensation Dynamics for Offshore Drilling Operation
}

\author{
Dave Kim ${ }^{1}$ and Namkug $\mathrm{Ku}^{2, *}(\mathbb{0}$ \\ 1 School of Engineering and Computer Science, Washington State University, Vancouver, WA 98686, USA; \\ kimd@wsu.edu \\ 2 Department of Naval Architecture and Ocean Engineering, Dong-Eui University, Busan 47340, Korea \\ * Correspondence: knk80@deu.ac.kr; Tel.: +82-51-890-2592
}

check for

updates

Citation: Kim, D.; Ku, N. Heave Compensation Dynamics for Offshore Drilling Operation. J. Mar. Sci. Eng. 2021, 9, 965. https://doi.org/ 10.3390/jmse9090965

Academic Editor: Nikolaos I. Xiros

Received: 31 July 2021

Accepted: 22 August 2021

Published: 6 September 2021

Publisher's Note: MDPI stays neutral with regard to jurisdictional claims in published maps and institutional affiliations.

Copyright: (c) 2021 by the authors. Licensee MDPI, Basel, Switzerland. This article is an open access article distributed under the terms and conditions of the Creative Commons Attribution (CC BY) license (https:// creativecommons.org/licenses/by/ $4.0 /)$.

\begin{abstract}
In this study, dynamic response analysis of a heave compensation system for offshore drilling operations was conducted based on multibody dynamics. The efficiency of the heave compensation system was computed using simulation techniques and virtually confirmed before being applied to drilling operations. The heave compensation system was installed on a semi-submersible and comprises several interconnected bodies with various joints. Therefore, a dynamics kernel based on multibody dynamics was developed to perform dynamic response analysis. The recursive Newton-Euler formulation was adopted to construct the equations of motion for the multibody system. Functions of the developed dynamics kernel were verified by comparing them with those from other studies. Hydrostatic force, linearized hydrodynamic force, and pneumatic and hydraulic control forces were considered the external forces acting on the platform of the semi-submersible rig and the heave compensation system. The dynamic simulation was performed for the heave compensation system of the semi-submersible rig for drilling operations up to $3600 \mathrm{~m}$ water depth. From the results of the simulation, the efficiency of the heave compensation system was evaluated to be approximately $96.7 \%$.
\end{abstract}

Keywords: heave compensation system; dynamic response analysis; drilling operation

\section{Introduction}

As the use of simulation tools to analyze mechanical systems has been increasing, the shipbuilding industry uses simulation techniques progressively when deploying various types of mechanical systems. For example, Figure 1a shows a goliath crane used to lift and transport heavy loads and essential facilities in shipyards. Figure $1 \mathrm{~b}$ shows a floating crane, whose capacity is usually greater than that of the goliath crane. As shown in the figure, unlike the goliath crane, the floating crane is operated in the sea. Figure $1 \mathrm{c}$ shows an offshore drilling rig. All these facilities are mechanical systems that must be analyzed concerning their dynamic aspects for accurate and reliable design. Among these three examples, we focused on the offshore drilling rig in this study.

A drilling rig is a massive offshore facility and comprises two parts: a platform and an offshore drilling system installed on the platform, as shown in Figure 2. One of the main functions of the offshore drilling system is to drill a hole in the seabed, which requires several sub-systems, including a drill string composed of steel pipes and a drill bit to dig the hole, as well as a hoisting system to raise and lower the drill string in and out of the hole. However, the semi-submersible moves owing to the effect of waves. The horizontal motions of the semi-submersible can be controlled by its mooring and dynamic positioning system, in contrast to the vertical motion. Therefore, a heave compensation system is required to keep the drill string stationary and unaffected by the heave motion. However, the motion and efficiency of the heave compensation system need to be evaluated with dynamic response analysis before applying it in offshore drilling operations. In this study, we aimed to develop a multibody dynamics kernel to perform dynamic response analysis 
and control of the heave compensation system of an offshore drilling rig by simulating the drilling operations under various wave loads.

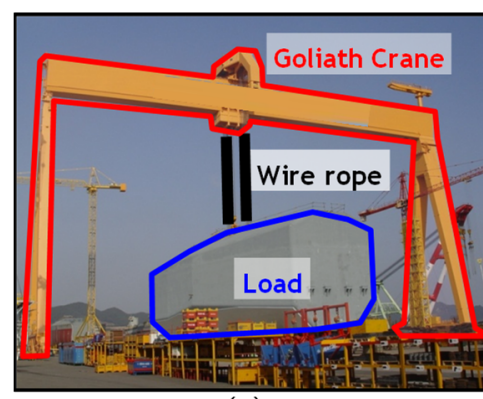

(a)

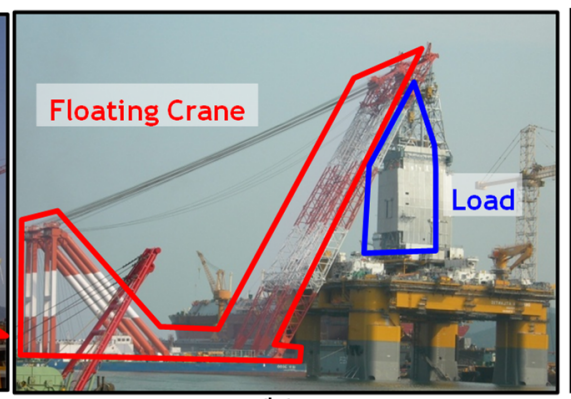

(b)

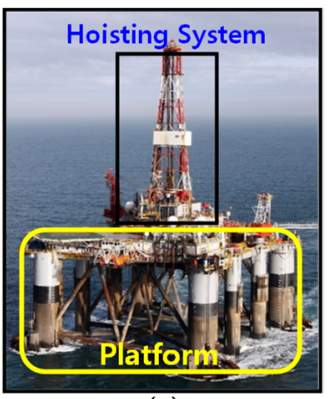

(c)

Figure 1. Various types of mechanical systems in the shipbuilding industry; (a) goliath crane; (b) floating crane; and (c) offshore drilling rig.

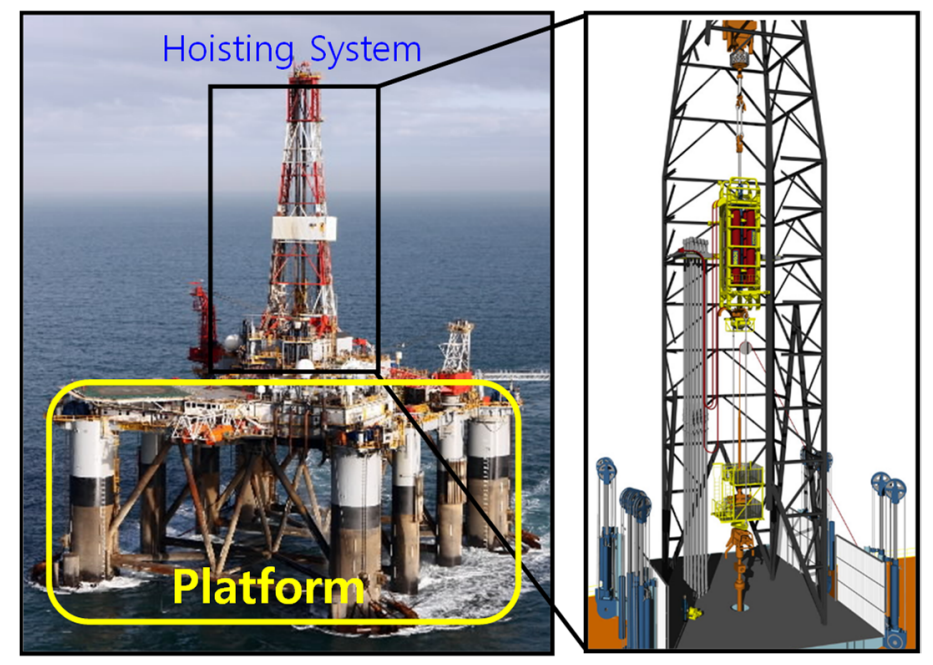

Figure 2. Offshore drilling rig and hoisting system.

\section{Related Works}

\subsection{Multibody Dynamics Kernels}

Automatic dynamic analysis of mechanical systems (ADAMS) is a bundled software that comprises various integrated programs that aid engineers in performing threedimensional kinematic and dynamic analyses of mechanical systems [1,2]. ADAMS generates equations of motion for multibody systems using augmented formulation. The users can define any multibody system comprising several rigid and flexible bodies interconnected by joints. ADAMS supplies various types of joints, such as fixed, revolute, and spherical. Various external forces can also be applied to the multibody systems; however, ADAMS cannot handle hydrostatic and hydrodynamic forces, which are the dominant forces exerted on the floating platform. Open dynamics engine (ODE) is an open-source library for simulating multibody dynamics [3]. Similar to ADAMS, ODE derives equations of motion for multibody systems using augmented formulation. However, ODE can treat only rigid bodies and not flexible ones. Moreover, ODE also cannot handle hydrostatic and hydrodynamic forces.

RecurDyn is a three-dimensional simulation software that combines dynamic response analysis and finite element analysis tools for multibody systems [4]. It is 2-20 times faster than other dynamic solutions due to its advanced fully recursive formulation. Simscape Multibody also supports multibody modeling. It is a module integrated in Matlab Simulink, and it is very convenient to use. However, although various joints and external forces 
can also be applied to the multibody systems, RecurDyn and Simscape cannot handle hydrostatic and hydrodynamic forces.

The hydrostatic force and hydrodynamic force can be calculated by considering the shape and motion of the semi-sub based on potential theory. For this calculation, it is usually necessary to use dedicated software, but it is not easy to integrate the software for with a commercial dynamics program. Therefore, we developed a dynamics kernel for the dynamic analysis of offshore structures such as a semi-submersible drilling rig or drillship. The equations of motion for multibody systems were derived using recursive formulation. Moreover, the external force calculation module can generate hydrostatic force by considering the nonlinear effects and linearized hydrodynamic force as external forces. Table 1 shows the features of the different dynamics kernels that were compared in this study.

Table 1. Comparison of features of the developed dynamics kernel in this study with commercial dynamics kernels.

\begin{tabular}{cccc}
\hline & This Study & ADAMS & RecurDyn \\
\hline $\begin{array}{c}\text { Multibody } \\
\text { formulation }\end{array}$ & $\begin{array}{c}\text { Recursive } \\
\text { formulation }\end{array}$ & $\begin{array}{c}\text { Augmented } \\
\text { formulation }\end{array}$ & $\begin{array}{c}\text { Recursive } \\
\text { formulation }\end{array}$ \\
\hline Various joints & $\mathrm{O}$ & $\mathrm{O}$ & $\mathrm{O}$ \\
\hline Flexible body & $\mathrm{X}$ & $\mathrm{O}$ & $\mathrm{O}$ \\
\hline Hydrostatic force & $\Delta$ & $\Delta$ & $\Delta$ \\
\hline $\begin{array}{c}\text { Linearized } \\
\text { hydrodynamic force }\end{array}$ & $\Delta$ & $\Delta$ & $\Delta$ \\
\hline
\end{tabular}

(O: Supported; $\Delta$ : The hydrostatic and hydrodynamic force can be only interfaced by the developer of the dynamics kernel, $X$ : Not supported).

\subsection{Dynamic Response Analysis of a Heave Compensation System}

There have been several studies related to heave compensation systems. As shown in Table 2, simulations of DSC were performed in all papers except Do's [5]. However, most studies considered the heave compensation system as a mass spring-damper system or lumped mass system. Only Beutlich's study modeled the DSC system as multibody system [6]. However, Beutlich's study did not treat the hydrostatic force, and hydrodynamic force. Therefore, in this study, a multibody dynamics kernel was developed and used for the dynamic analysis of the system and the hydrostatic and hydrodynamic forces were considered as an external force.

Table 2. Comparison of the features of this study with those of other studies.

\begin{tabular}{|c|c|c|c|c|c|c|c|c|}
\hline & & This Research & Albers [7] & \multicolumn{2}{|c|}{ Hatleskog [8] } & Do [5] & Lumeng [9] & Beutlich [6] \\
\hline & Object & $\begin{array}{l}\text { DSC for } \\
\text { offshore } \\
\text { drilling rig }\end{array}$ & $\begin{array}{l}\text { DSC for } \\
\text { offshore } \\
\text { drilling rig }\end{array}$ & \multicolumn{2}{|c|}{$\begin{array}{l}\text { DSC for offshore } \\
\text { drilling rig }\end{array}$} & $\begin{array}{l}\text { AHC for } \\
\text { offshore } \\
\text { drilling rig }\end{array}$ & $\begin{array}{l}\text { DSC for } \\
\text { offshore } \\
\text { drilling rig }\end{array}$ & $\begin{array}{l}\text { DSC for } \\
\text { offshore } \\
\text { drilling rig }\end{array}$ \\
\hline \multicolumn{2}{|c|}{ Equation of motion } & Multibody & $\begin{array}{l}\text { Mass spring- } \\
\text { damper system }\end{array}$ & \multicolumn{2}{|c|}{$\begin{array}{c}\text { Mass spring- } \\
\text { damper system }\end{array}$} & $\begin{array}{l}\text { Mass spring- } \\
\text { damper system }\end{array}$ & $\begin{array}{l}\text { Lumped } \\
\text { mass } \\
\text { method }\end{array}$ & Multibody \\
\hline \multirow{3}{*}{$\begin{array}{l}\text { External } \\
\text { force }\end{array}$} & $\begin{array}{l}\text { External force } \\
\text { exerted on } \\
\text { platform } \\
{ }^{*} \text { : forced } \\
\text { oscillation) }\end{array}$ & $\begin{array}{c}\text { Hydrostatic } \\
\text { force, } \\
\text { hydrodynamic } \\
\text { force }\end{array}$ & $X^{*}$ & & & $X^{*}$ & $\begin{array}{c}\mathrm{O} \\
\text { (Physical } \\
\text { test bed) }\end{array}$ & $X^{*}$ \\
\hline & \multirow[b]{2}{*}{$\begin{array}{l}\text { DSC control } \\
\text { force }\end{array}$} & Spring & $\mathrm{O}$ & $\mathrm{O}$ & $\mathrm{O}$ & $\mathrm{O}$ & $\mathrm{O}$ & $\mathrm{O}$ \\
\hline & & $\begin{array}{l}\text { Implementation } \\
\text { of the spring } \\
\text { mechanism }\end{array}$ & Pneumatic & $\begin{array}{l}\text { Constant } \\
\text { coefficient }\end{array}$ & Pneumatic & $\begin{array}{l}\text { Active } \\
\text { control }\end{array}$ & Pneumatic & Pneumatic \\
\hline
\end{tabular}




\section{Heave Compensation System Equipment}

\subsection{Configuration of an Offshore Drilling System}

The primary function of the offshore drilling system of the offshore drilling rig is to drill a hole in the seabed, which requires multiple pieces of equipment. The equipment systems used in drilling a hole include six main categories: the hoisting system, heave compensation system, pipe handling system, BOP and X-mas tree handling system, circulation system, and power system, as shown in Figure 3.

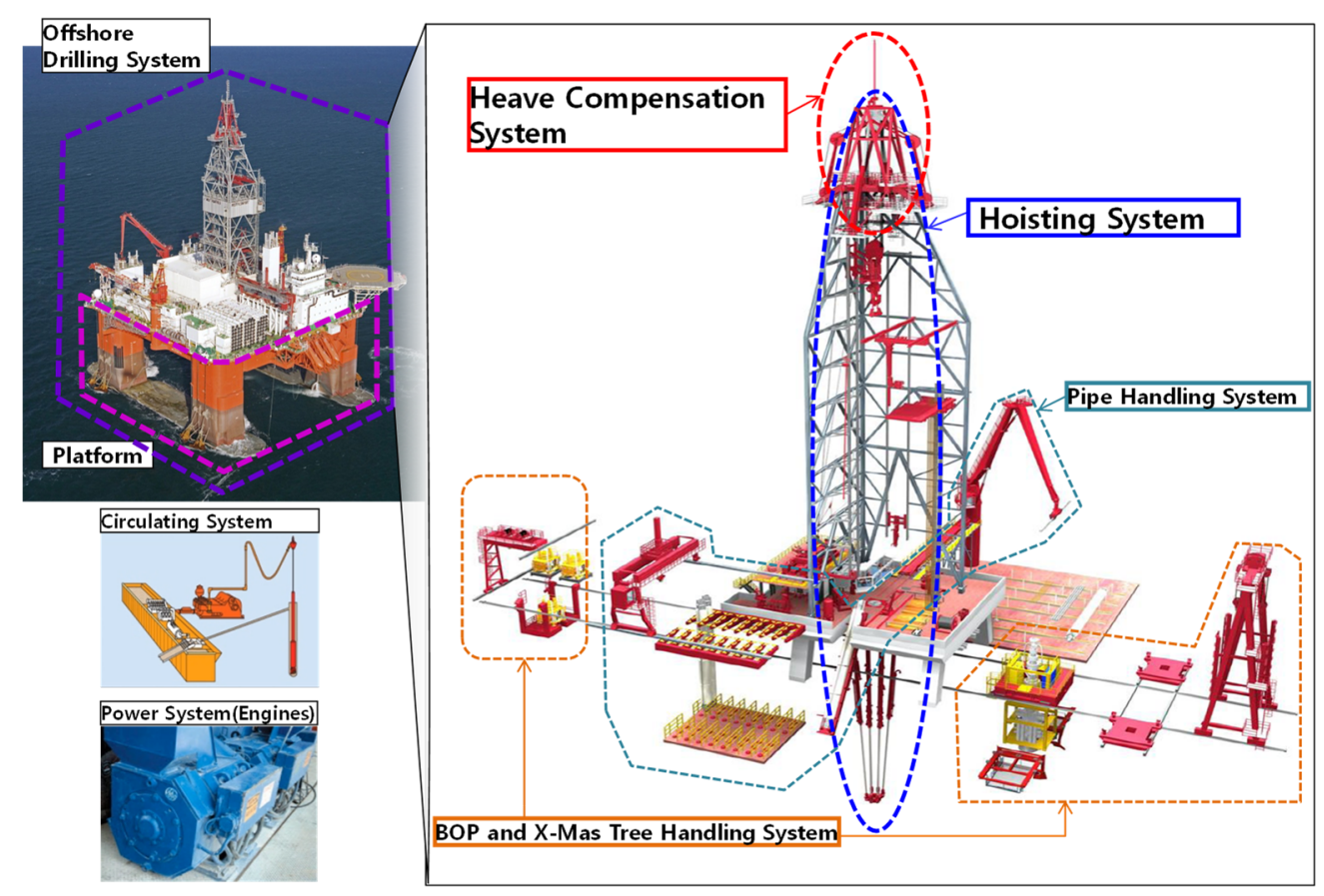

Figure 3. Six main categories of equipment systems on an offshore drilling system.

Among these main categories, we focused on the heave compensation system in this study. In the following subsection, the heave compensation system is explained in detail [10].

\subsection{Components of a Heave Compensation System}

The heave compensation system is composed of a drill string compensator (DSC) and an active heave compensator (AHC), as shown in Figure 4.

The DSC is a passive heave compensator, mounted on top of the hoisting system, to minimize the effects of the drill rig heave on the drill string. In this paper, we modeled and analyzed "drill string compensator" from "Aker solutions". The DSC supports the weight of the drill string, which comprises 1200-m steel pipes and a drill bit.

As pneumatic and hydraulic systems are capable of transmitting a large amount of power, the DSC employs a combined pneumatic and hydraulic system that acts as a low-ware spring using air pressure, which is controlled to vary the load.

The side and front views of the DSC are shown in Figure 5. The side view shows two inclined cylinders that support the crown block connected to the drill string. The DSC also has two mounted rocker arms to support four-wire sheaves. 


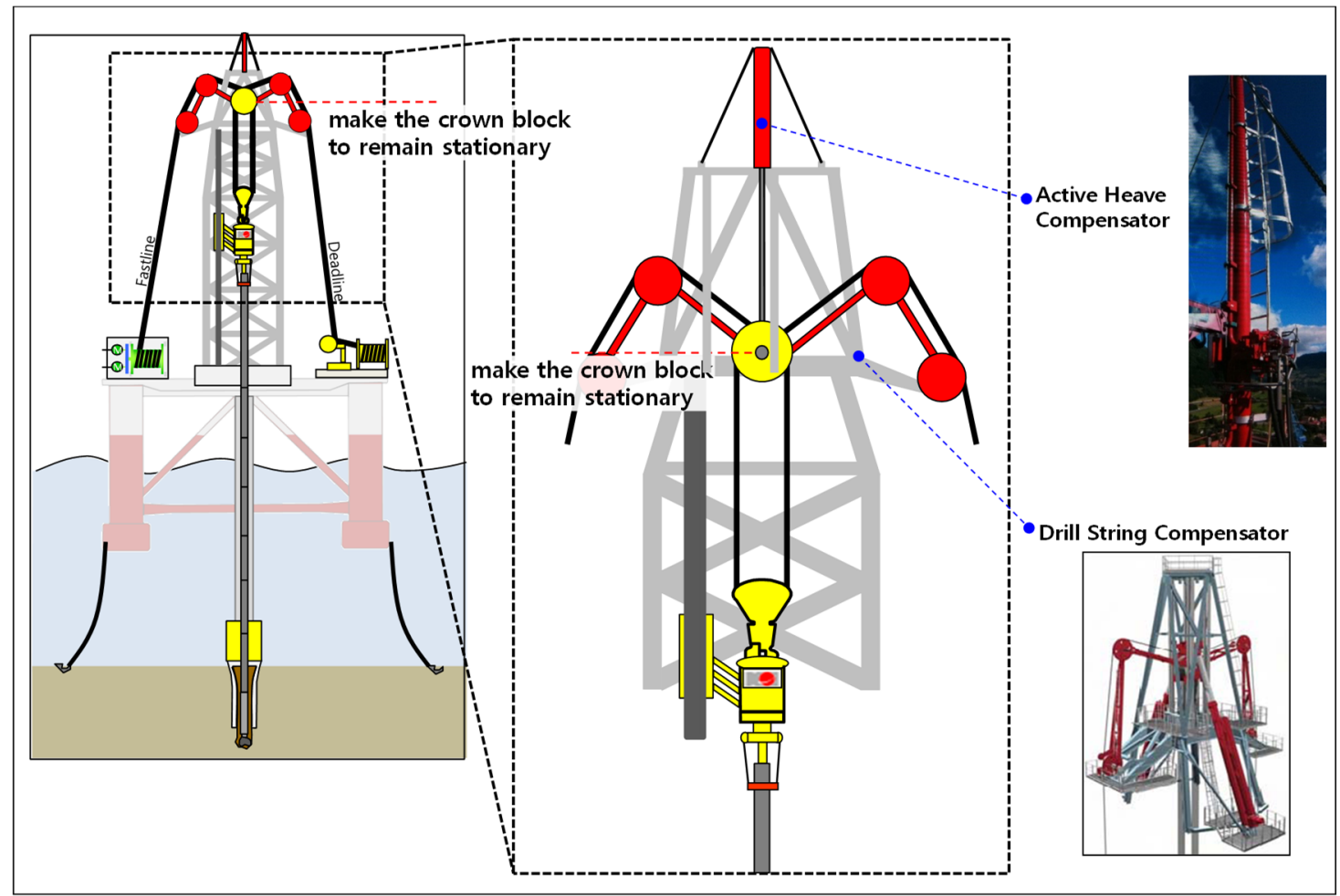

Figure 4. Components of a heave compensation system.
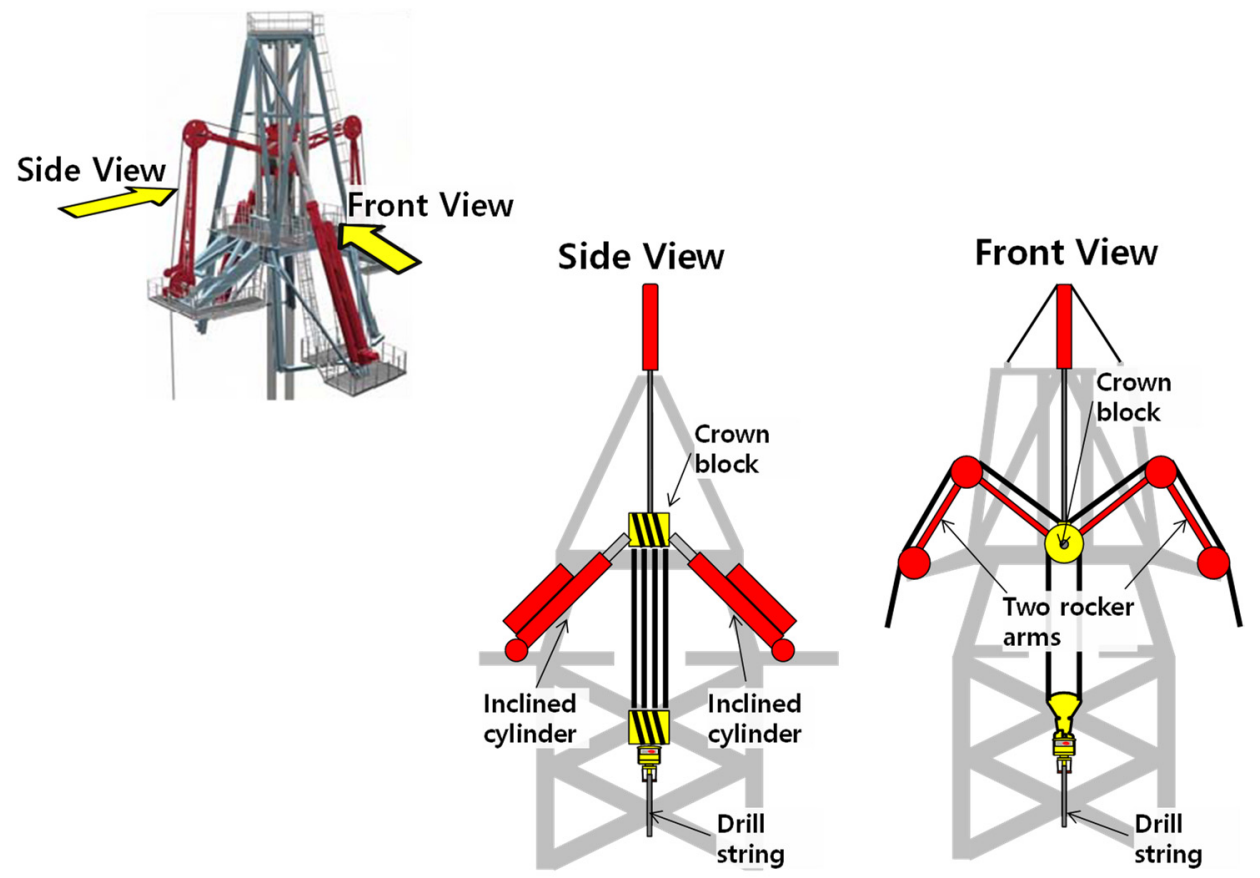

Figure 5. Side and front views of the drill string compensator.

The compensator and the suspended load, including the crown block and the drill string, may be considered a spring-mass system. At this moment, the DSC can be regarded as a pneumatic spring. This is achieved by suspending the crown block from a large piston in the cylinder connected to a high-pressure air pressure vessel (APV). The volume of the air can be increased or decreased to alter the spring rate. Moreover, the mean pressure of the air is controlled to vary the load that can be supported [6]. 
As shown in Figure 6a,b, using inclined cylinders, the force in the direction of the cylinders changes depending on the heave. Furthermore, as shown in Figure $6 c, d$, the rocker arms allow a full stroke of the compensator with a constant length of the wireline within the system. The rocker arm sheaves are equipped with a wire guide to prevent wire derailing. Therefore, the DSC provides stable positions for the crown block and the drill string in reference to the seabed.

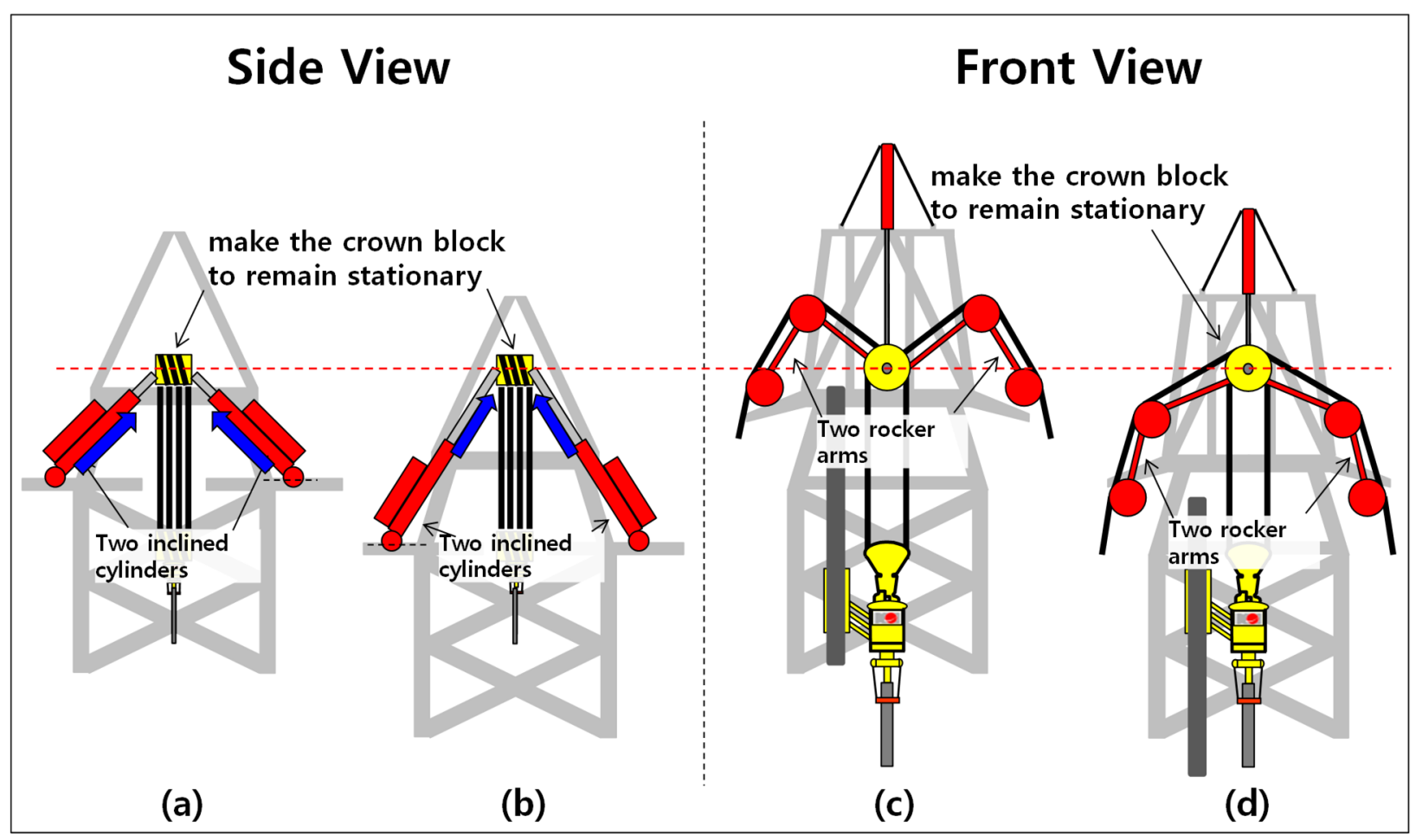

Figure 6. The operating mechanism of the drill string compensator.

However, because of the DSC seal friction between the inner wall and the cylinder's piston, which tends to enforce the heave disturbance, an AHC is additionally required to overcome the disturbance. However, in ideal conditions, the DSC can support most of the loads. The efficiency of the heave compensation system is more than $95 \%$ for any ship motion.

The explained heave compensation system is a collection of rigid bodies interconnected with various joints that limit the relative motion of pairs of bodies. It can be considered a multibody system. Because the mechanism of the heave compensation system is not simple, their body connections should be modeled precisely for accurate simulation. Therefore, a multibody dynamics kernel was developed in this study for the dynamic analysis of the system.

\section{Multibody Dynamics Based on Recursive Formulation}

In this section, we describe the developed multibody dynamics kernel based on recursive formulation.

\subsection{Forward and Inverse Dynamics}

The dynamics of a rigid-body system can be described by the equations of motion, which specify the relationship between the forces acting on the system and the accelerations produced. In this section, we focus on the algorithms for the following two particular calculations.

- Forward dynamics: The calculation of the acceleration response of a given rigid-body system to a given applied force; 
- Inverse dynamics: The calculation of the force that must be applied to a given rigidbody system to produce a given acceleration response.

Both forward and inverse dynamics are implemented using recursive formulas for the simulation [11]. The equations of motion for each body of the multibody system based on recursive formula can be summarized as below.

$$
\begin{gathered}
\hat{v}=i^{i} X_{i-1} \cdot \hat{v}_{i-1}+S_{i} \cdot \dot{q}_{i} \\
\hat{a}_{i}=i^{i} X_{i-1} \cdot \hat{a}_{i-1}+S_{i} \cdot \ddot{q}_{i}+\dot{S}_{i} \cdot \dot{q}_{i}+\hat{v}_{i} \times S_{i} \cdot \dot{q}_{i} \\
\hat{f}_{i}^{B}=\hat{I}_{i} \cdot \hat{a}_{i-1}+\hat{v}_{i-1} \times \hat{I}_{i} \cdot \hat{v}_{i} \\
\hat{f}_{i}=\hat{f}_{i}^{B}+i^{i} X_{i+1}^{*} \cdot \hat{f}_{i+1}-\hat{f}_{i}^{\text {ext }} \\
\tau_{i}=S_{i}^{T} \cdot \hat{f}_{i}
\end{gathered}
$$

where:

$\hat{v}_{i}$ : Velocity vector of body $i$ (six components);

$\hat{a}_{i}$ : Acceleration vector of body $i$ (six components);

$q_{i}$ : Generalized coordinate (joint values);

$S_{i}$ : Velocity transformation matrix;

$I_{i}$ : Mass and mass moment of inertia of body $i$;

$\hat{f}_{i}^{B}$ : Resultant force exerted on body $i$;

$\hat{f}_{i}^{\text {ext }}$ : External force exerted on body $i$;

$\hat{f}_{i}:$ Force across the joint $i$;

$\tau_{i}$ : Force generated by joint $i$ (generalized force);

$i^{i} X_{i-1}$ : Coordinate transformation matrix.

In inverse dynamics, as the positions $q_{i}$, velocities $\dot{q}_{i}$, and accelerations $\ddot{q}_{i}$ of generalized coordinates are provided, the velocities $\hat{v}_{i}$ and accelerations $\hat{a}_{i}$ of each body can be computed. Furthermore, the forces $\hat{f}_{i}$ and the generalized forces $\tau_{i}$, which are exerted on each link, can also be computed in a recursive fashion [11,12].

Equations (1)-(5) can be rearranged into Equations (6)-(9), which are the equations of motion for the forward dynamics of the multibody system based on recursive formulation.

$$
\begin{gathered}
\hat{a}_{i}=i^{i} X_{i-1} \cdot \hat{a}_{i-1}+S_{i} \cdot \ddot{q}_{i}+c_{i} \\
\ddot{q}_{i}=\left(S_{i}^{T} \hat{I}_{i}^{A} S_{i}\right)^{-1}\left(\tau_{i}-S_{i}^{T}\left(I_{i}^{A}\left(i^{i} X_{i-1} \hat{a}_{i-1}+c_{i}\right)+p_{i}^{A}\right)\right) \\
\hat{I}_{i}^{A}=\hat{I}_{i}+X_{i+1}^{*} \cdot \hat{I}_{i+1}^{A} \cdot i^{i+1} X_{i}-i^{i} X_{i+1}^{*} \cdot \hat{I}_{i+1}^{A} \cdot S_{i+1} \cdot\left(S_{i+1}^{T} \hat{I}_{i+1}^{A} S_{i+1}\right)^{-1} S_{i+1}^{T} \hat{I}_{i+1}^{A} i^{i+1} X_{i}
\end{gathered}
$$

$$
p_{i}^{A}=p_{i}+i^{i} X_{i+1}^{*} \cdot p_{i+1}^{A}+i^{i} X_{i+1}^{*} \cdot \hat{I}_{i+1}^{A} \cdot c_{i+1}+i^{i} X_{i+1}^{*} \cdot \hat{I}_{i+1}^{A} \cdot S_{i+1} \cdot\left(S_{i+1}^{T} \hat{I}_{i+1}^{A} S_{i+1}\right)^{-1}\left(\tau_{i+1}-S_{i+1}^{T}\left(I_{i+1}^{A} c_{i+1} p_{i+1}^{A}\right)\right)
$$

where:

$$
\begin{gathered}
c_{i}=\dot{S}_{i} \cdot \dot{q}_{i}+\hat{v}_{i} \times S_{i} \cdot \dot{q}_{i} \\
p_{i}=\hat{v}_{i} \times I_{i} \cdot \hat{v}_{i}-\hat{f}_{i}^{e x t}
\end{gathered}
$$

The multibody dynamics kernel was developed based on the equations of motion for the forward and inverse dynamics. Equations (6)-(11) are used to calculate the acceleration of the multibody when an external force is applied. Numerical integration was performed to calculate position and velocity by integrating acceleration, and the RK4 (Runge-Kutta fourth order) method was used for it. 


\subsection{Verification of the Dynamics Kernel}

We used a test model to verify the developed dynamics kernel with the dynamic codes developed in the 1980s. As shown in Figure 7, the test model was a multibody system comprising eight bodies and ten revolute joints. Additionally, the system had three closed loops.

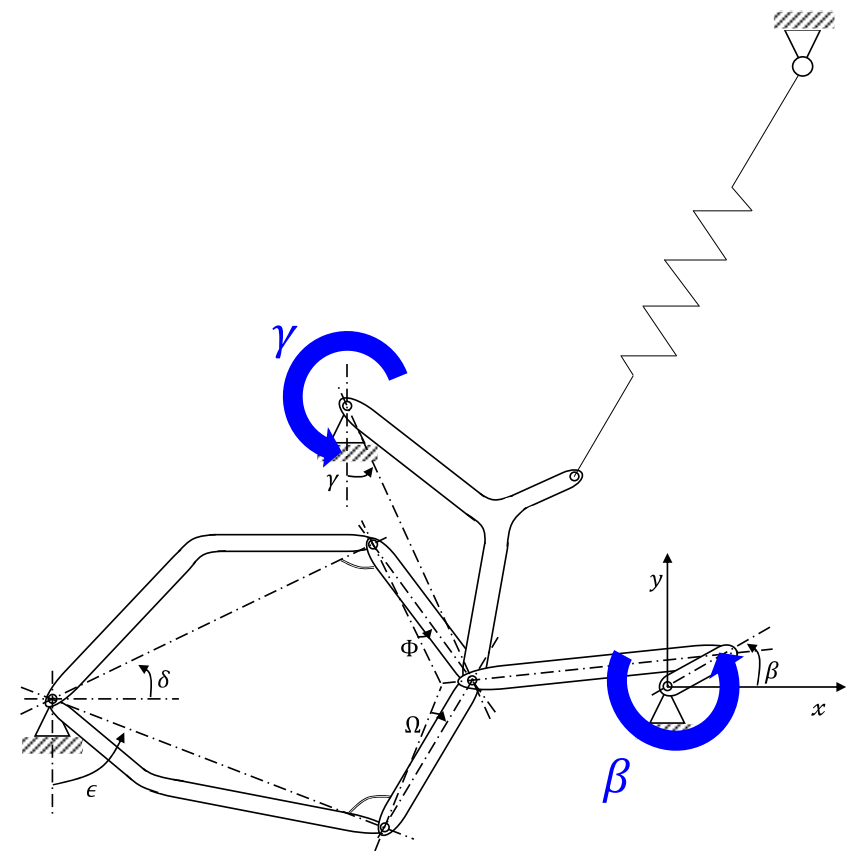

Figure 7. Generalized coordinates $\beta$ and $\gamma$ of the multibody system.

The position, velocity, and acceleration of the generalized coordinates $\beta$ and $\gamma$ illustrated in Figure 8 were compared with those obtained from [2]. As shown in Figure 8, our simulation results matched highly with the reference data, and it shows the same level of calculation performance as the module developed in other papers.

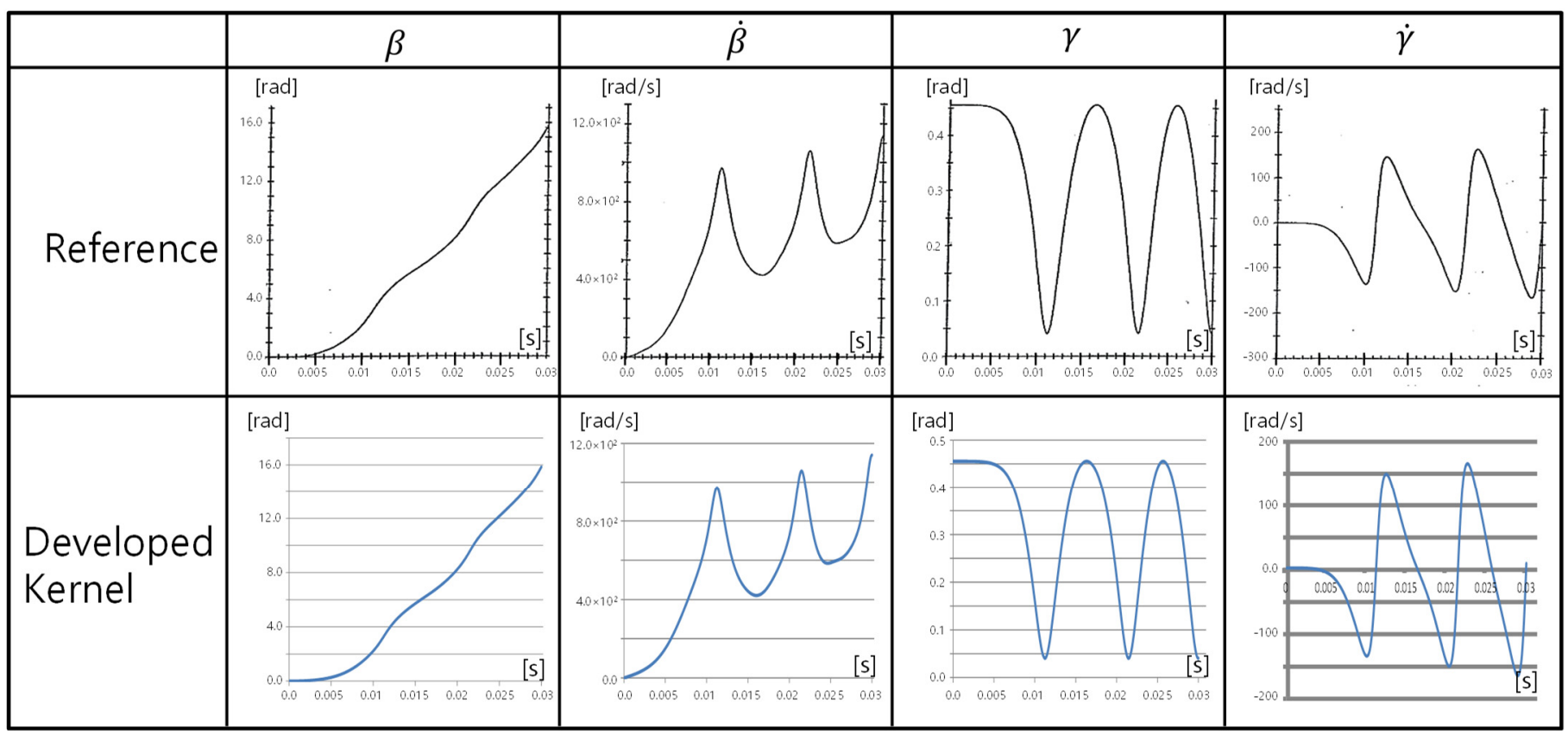

Figure 8. Simulation results of the position and velocity of the generalized coordinates $\beta$ and $\gamma$ compared with those obtained from reference. 


\section{Construction of Mathematical Model}

\subsection{Mechanical Configuration of the Hoisting and Compensation System}

The mechanical configuration of the hoisting and heave compensation system comprises bodies and joints. The bodies are considered rigid bodies that are interconnected with several types of joints. The types of joints that are used to construct the hoisting and heave compensation system are as follows.

- Fixed joint: A joint that can fix one body to another; this joint has a zero degree of freedom;

- Revolute joint: A joint that can rotate around one axis; this joint has one degree of freedom;

- Slide joint: A joint that can translate along one axis; this joint has one degree of freedom.

Figure 9 shows the (2) DSC, (5) top drive, and (7) AHC in detail. The DSC comprises eight bodies, and the top drive and AHC comprise two bodies each.

The DSC contains two cylinders (2)-(1) (4)) and two rocker arms (2)-(5) (8)). In the side view shown in Figure 9, the cylindrical tubes (2)-(1) and (2)-(3) are connected to the (2) drilling structure (derrick) with revolute joints and the cylindrical rods (2)-(2) and (2)-(4)) with slide joints. The ends of the cylindrical rods are connected to the (3) crown block with revolute joints. The front view shows that the two rocker arms contain two links each. The bottom ends of the links (2)-(5) and (2)-(7)) are connected to the (1) derrick with revolute joints, and the other ends are connected to links (2)-(6) and (2)-(8) with revolute joints. Links (2)-(6) and (2)-(8) are also connected to the (3) crown block with revolute joints.

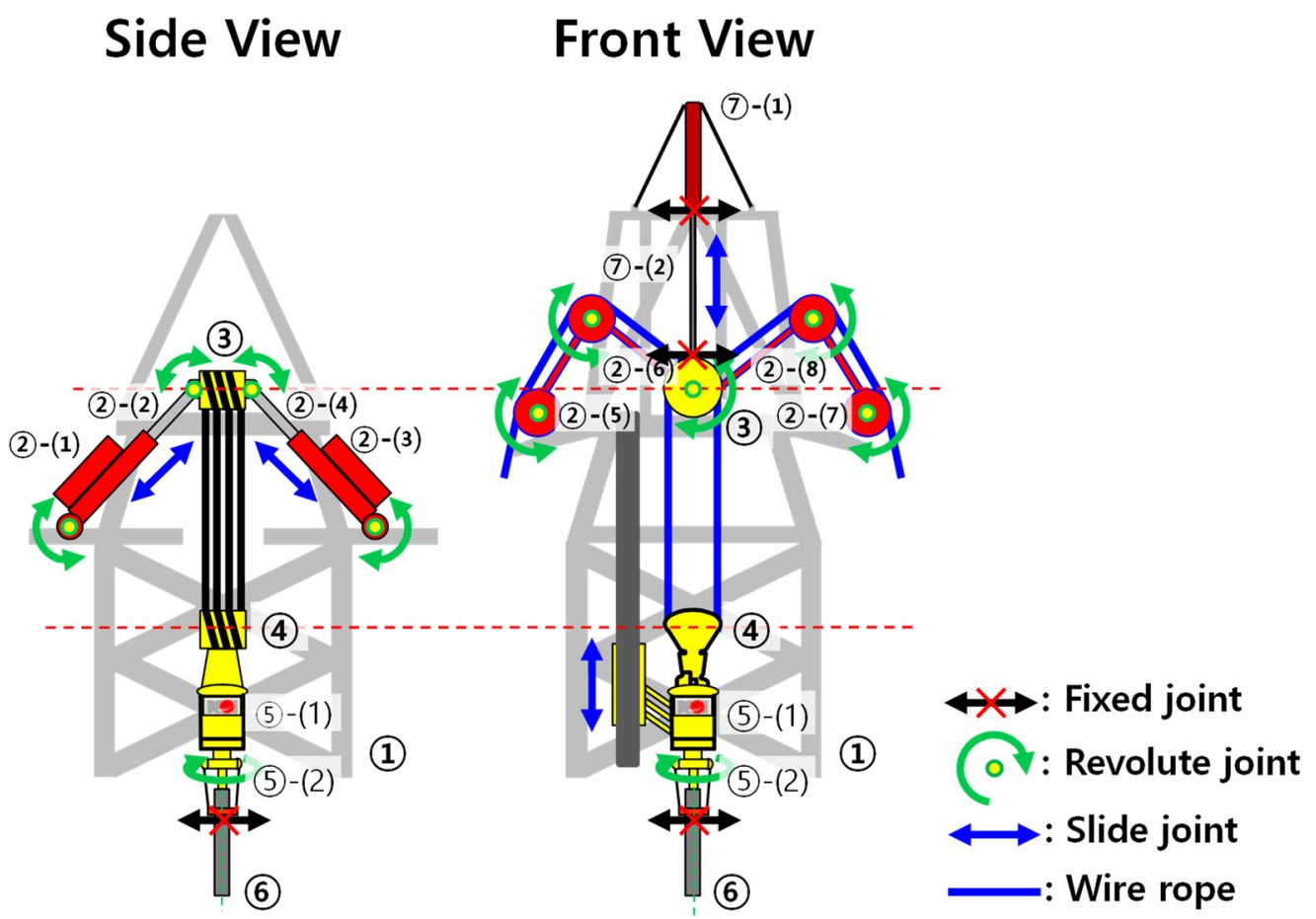

Figure 9. Mechanical configuration of the heave compensation system.

The tube of the AHC (7)-(1) is connected to the derrick with a fixed joint and to the rod (7)-(2) with a slide joint. The other end of the rod (7)-(2) is connected to the crown block with a fixed joint.

\subsection{Pneumatic and Hydraulic Control of the Heave Compensator}

The heave compensation system uses pneumatic and hydraulic systems, which are suitable for transmitting a large amount of power over great distances. 
The DSC is a combined pneumatic and hydraulic system that acts as a low-rate spring using air pressure, which is controlled to vary the load that can be supported. Therefore, it is called a passive heave compensator. The DSC mainly comprises the cylinder, accumulator, and APV. The AHC is the hydraulic system that is used to compensate for the seal friction of the DSC to maintain the stationary position of the crown block. In this study, we focused on the effect of the volume of the APV, which is one of the DSC components [13].

For the pneumatic and hydraulic control model design, the research of McNary [14] was referred to. This research shows that the normal schematic of the pneumatic and hydraulic control model consists of APVs, accumulators, cylinders, drain, isolation valves, ventilation valves, etc.

However, we simplified the schematic diagram as shown in Figure 10, because the essential components are the APVs, accumulators, and cylinders in the pneumatic and hydraulic control model.

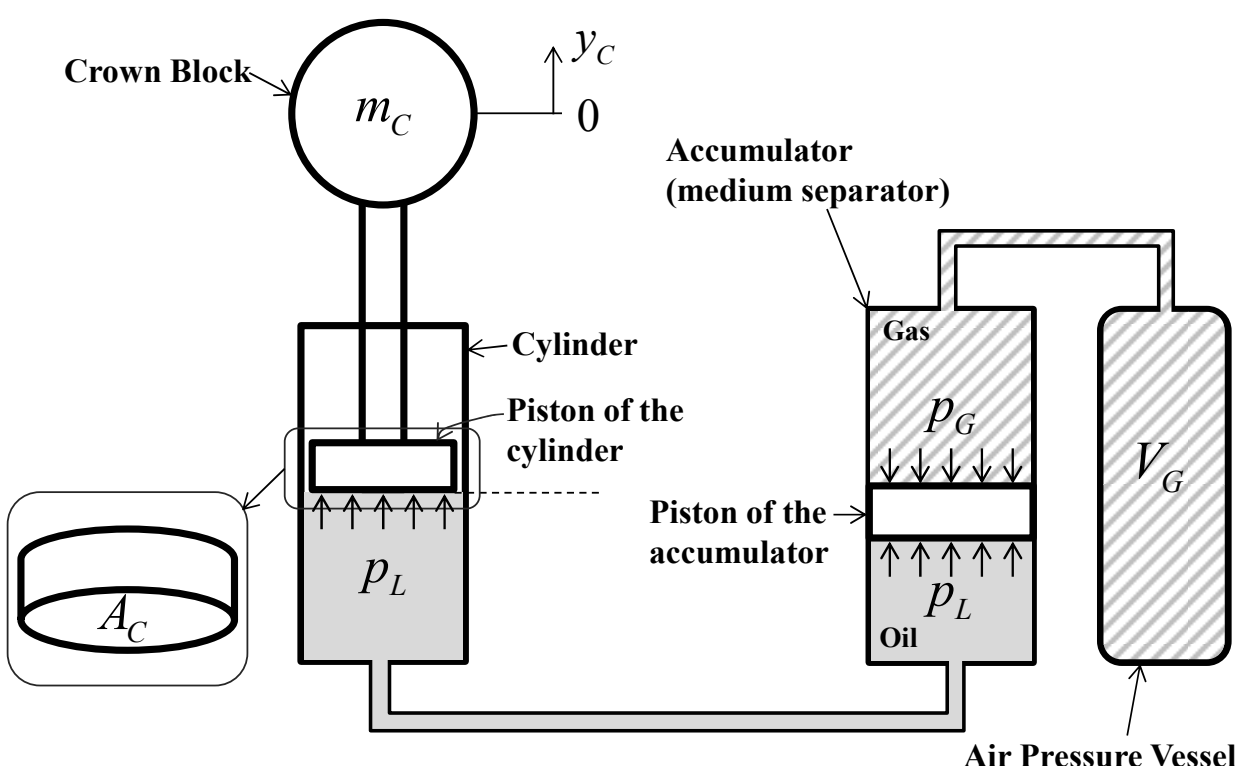

Figure 10. Simplified pneumatic and hydraulic control model.

In Figure $10, p_{G}$ and $p_{L}$ are the pressure values of the gas and oil, respectively, $V_{G}$ is the volume of the gas, $A_{C}$ is the area of the piston, $y_{C}$ is the position of the crown block, and $y_{p}$ is the piston's position. As the crown block pushes the cylinder piston downwards, the air volume reduces, and pressure increases until the increase in the pressure balances the load. Conversely, as the piston moves upwards, the total volume increases, effectively reducing the pressure until the decrease in the pressure balances the load. In any continuous compression process, the relationship between the absolute gas pressure $p_{G}$ and the gas volume $V_{G}$ is expressed by the following equation using the polytropic coefficient $n$.

$$
\begin{gathered}
p_{G} \cdot V_{G}^{n}=\text { Const. } \\
F_{D S C}=A_{C} \cdot p_{G}
\end{gathered}
$$

By using these two equations, the equation for calculating pneumatic force can be derived as follows.

$$
F_{D S C}=A_{C} \cdot p_{G, 0} \cdot\left(\frac{V_{G, 0}}{V_{G, 0}+A_{C} \cdot\left(y_{C}-y_{p}\right)}\right)^{n}
$$

For the initial values of the gas volume and pressure $p_{G, 0}$ and $V_{G, 0}$, the data of the DSC from Daewoo Shipbuilding \& Marine Engineering is referred to [15]. 


\subsection{Construction of Equations of Motion for the Heave Compensation System}

As explained in the previous section, the heave compensation system comprises many mechanical parts such as inclined cylinders and rocker arms, interconnected by various types of joints, as shown in Figure 11.

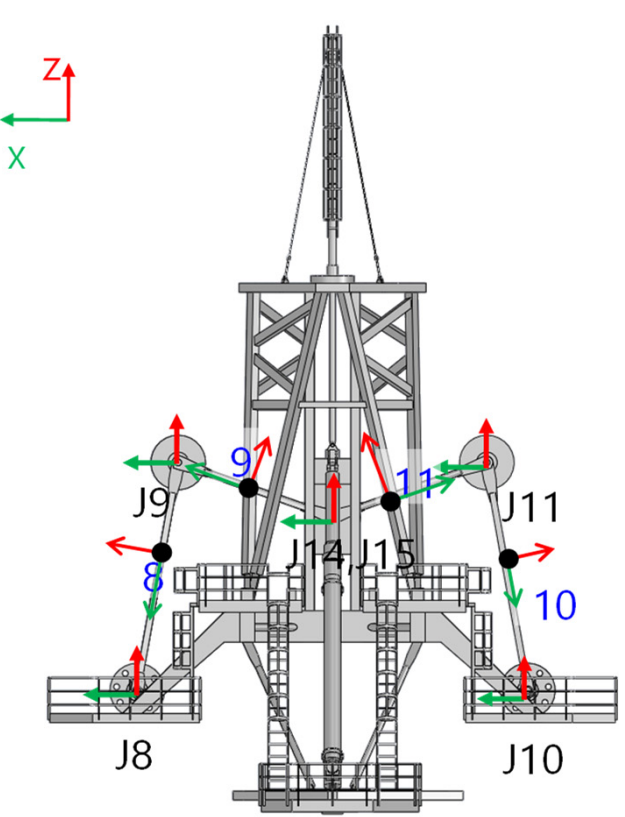

Figure 11. Joints and coordinate systems of heave compensation system.

In this study, the heave compensation system was modeled as 11 rigid bodies and 15 joints. Therefore, after including the semi-submersible and the hoisting tower, the socalled "derrick" the whole system was modeled as 13 rigid bodies and 17 joints. The drill string was modeled assuming a 12,000-m drill pipe, 200-m heavily walled drill pipe, and 100-m drill collar [16].

For simulating the external forces, the hydrostatic force, hydrodynamic force, and control force were considered. In contrast with the commercially available dynamics kernels, the kernel developed in this study can handle both hydrostatic and hydrodynamic forces. The hydrostatic force of the semi-submersible was calculated by considering an instantaneous position and orientation. The linearized hydrodynamic force was converted from the frequency domain to the time domain with convolution integral. The "added mass" and "damping coefficient" of semi-submersible in the frequency domain were calculated using WADAM, a commercial software [17].

\section{Dynamic Analysis of the Heave Compensation System}

For the numerical simulation, the horizontal motions were assumed to be controlled by the mooring and dynamic positioning system. In addition, a set of waves with an amplitude of $4 \mathrm{~m}$, a period of $10 \mathrm{~s}$, and a wavelength of $156 \mathrm{~m}$ was applied. Figure 12 shows the results of the geometrical modeling. 


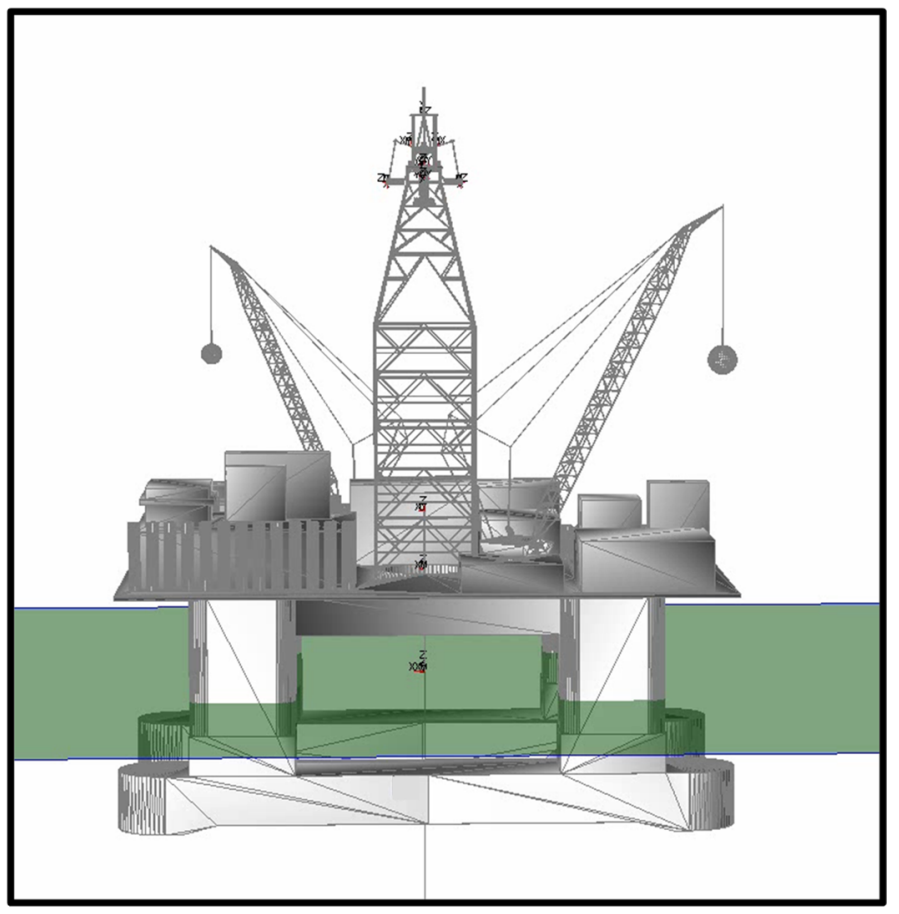

Figure 12. Visualization of the dynamic response of the heave compensation system.

Figures 13-16 show the dynamic responses of the semi-submersible and crown block. The simulation results show that the amplitude of the heave motion of the crown block is between 0.0049 and $0.0389 \mathrm{~m}$, and that of the semi-submersible is between 0.1491 and $1.1931 \mathrm{~m}$. Thus, the efficiency of the heave compensation system was approximately $96.7 \%$, which is similar to the $95 \%$ performance efficiency generally observed for these compensation systems.

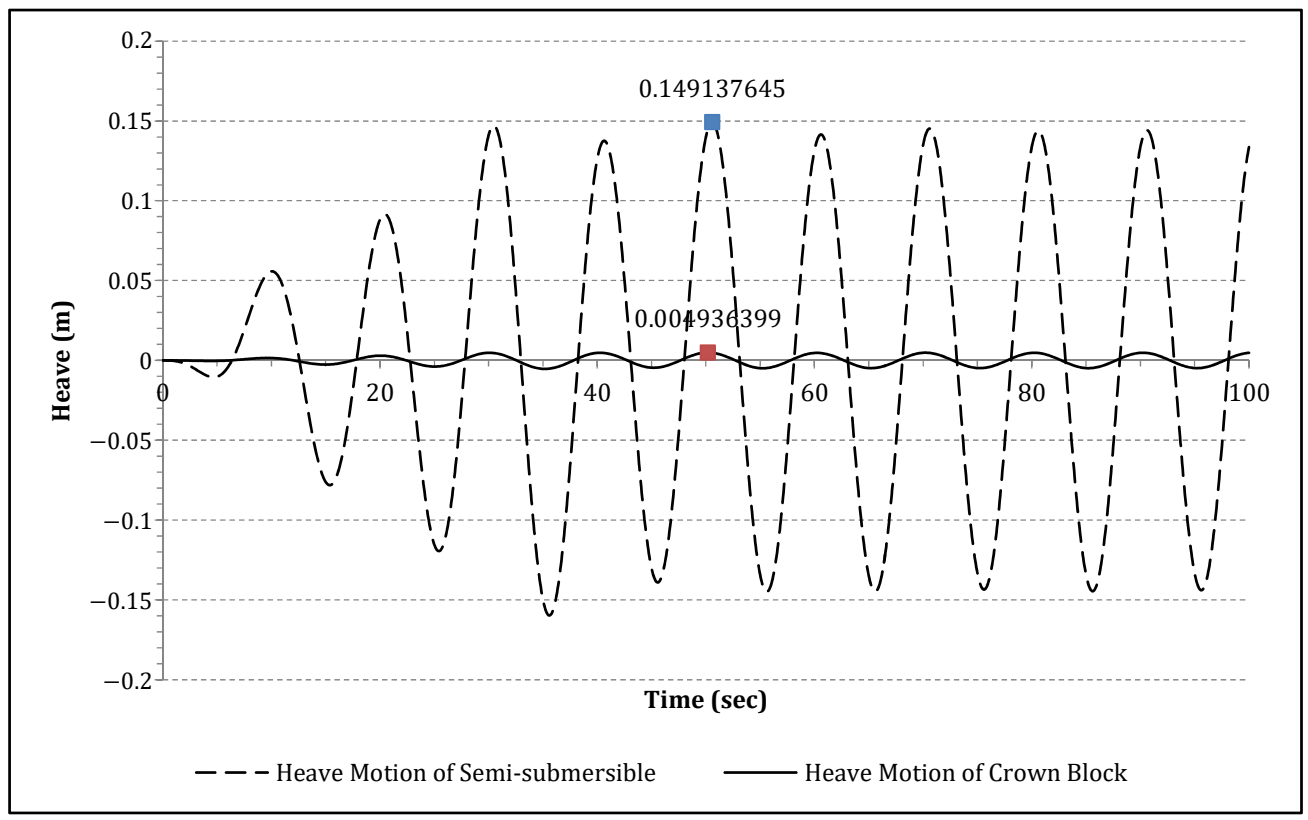

Figure 13. Dynamic response analyses of the semi-submersible and crown block with the heave compensation system for a 1-m wave amplitude. 


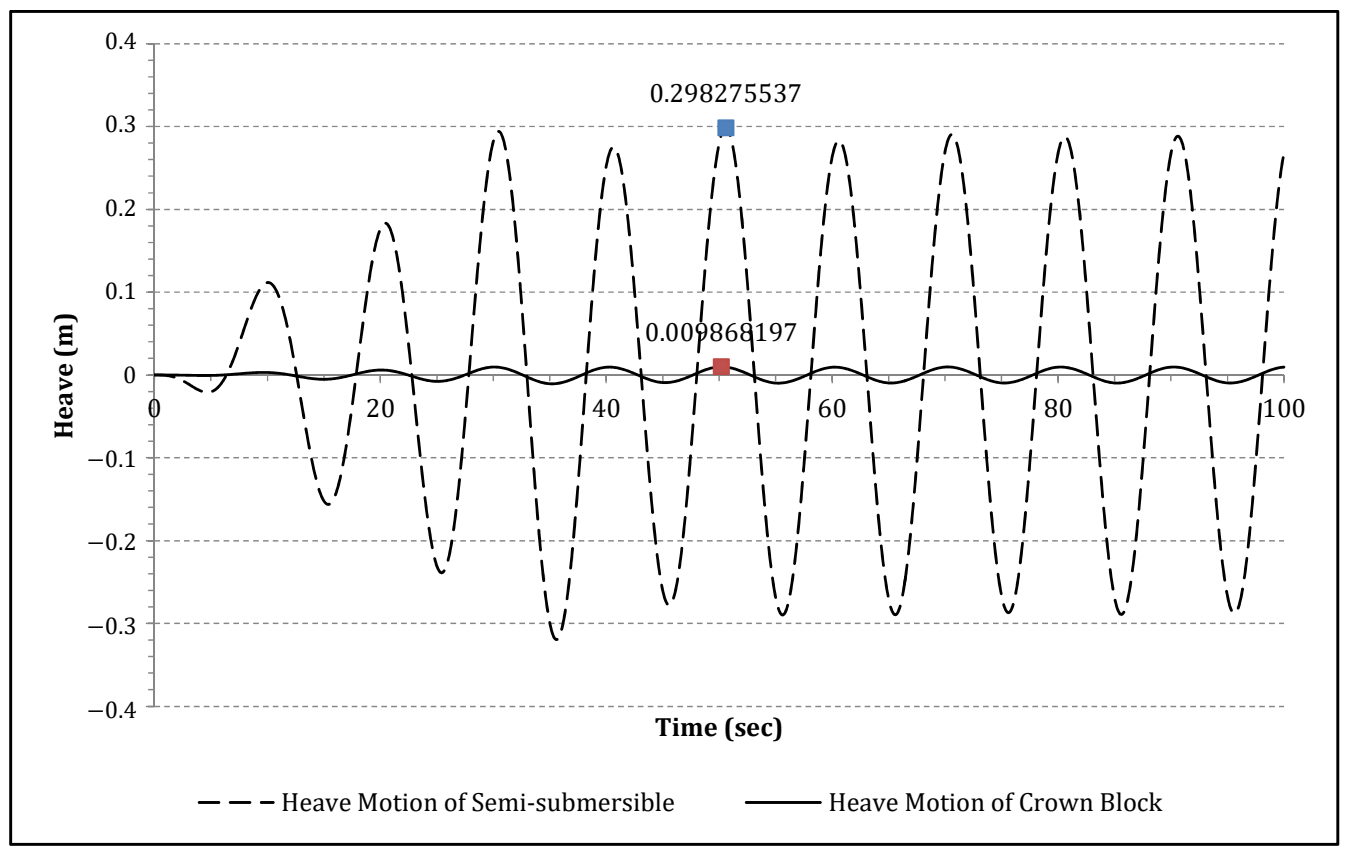

Figure 14. Dynamic response analyses of the semi-submersible and crown block with the heave compensation system for a 2-m wave amplitude.

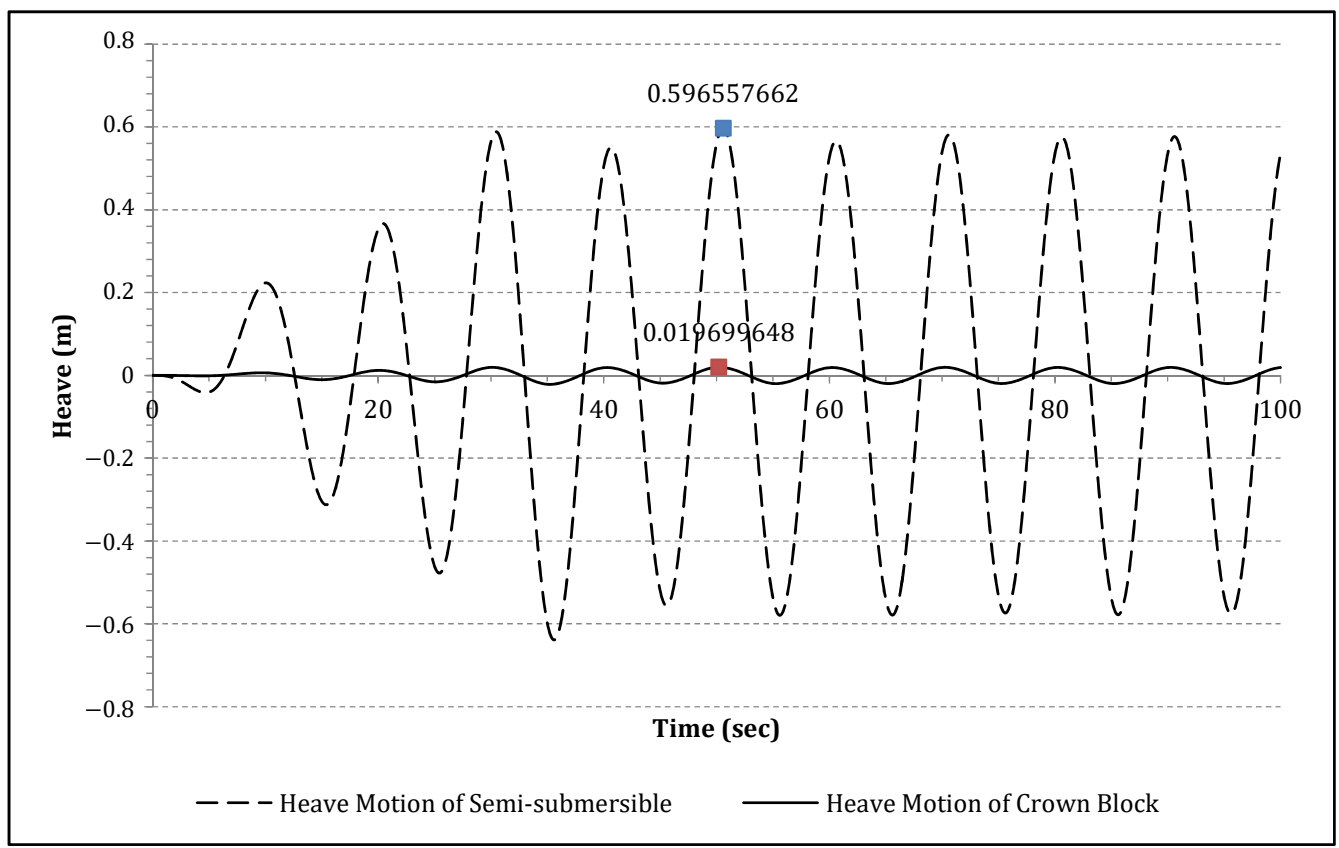

Figure 15. Dynamic response analyses of the semi-submersible and crown block with the heave compensation system for a 4-m wave amplitude.

After developing the simulation system, a parametric study was also performed, and the results can be utilized to design the pneumatic system of the heave compensation system. For the parametric study, waves with a period of $10 \mathrm{~s}$, a wavelength of $156 \mathrm{~m}$, and an amplitude of $3 \mathrm{~m}$ were applied for varying volumes of the APV. The results of the simulation are as follows. In Figure 21, since the force exerted by the heave compensation system and gravity are almost in equilibrium, irregular motion independent of the semi-sub periodic motion was observed. 


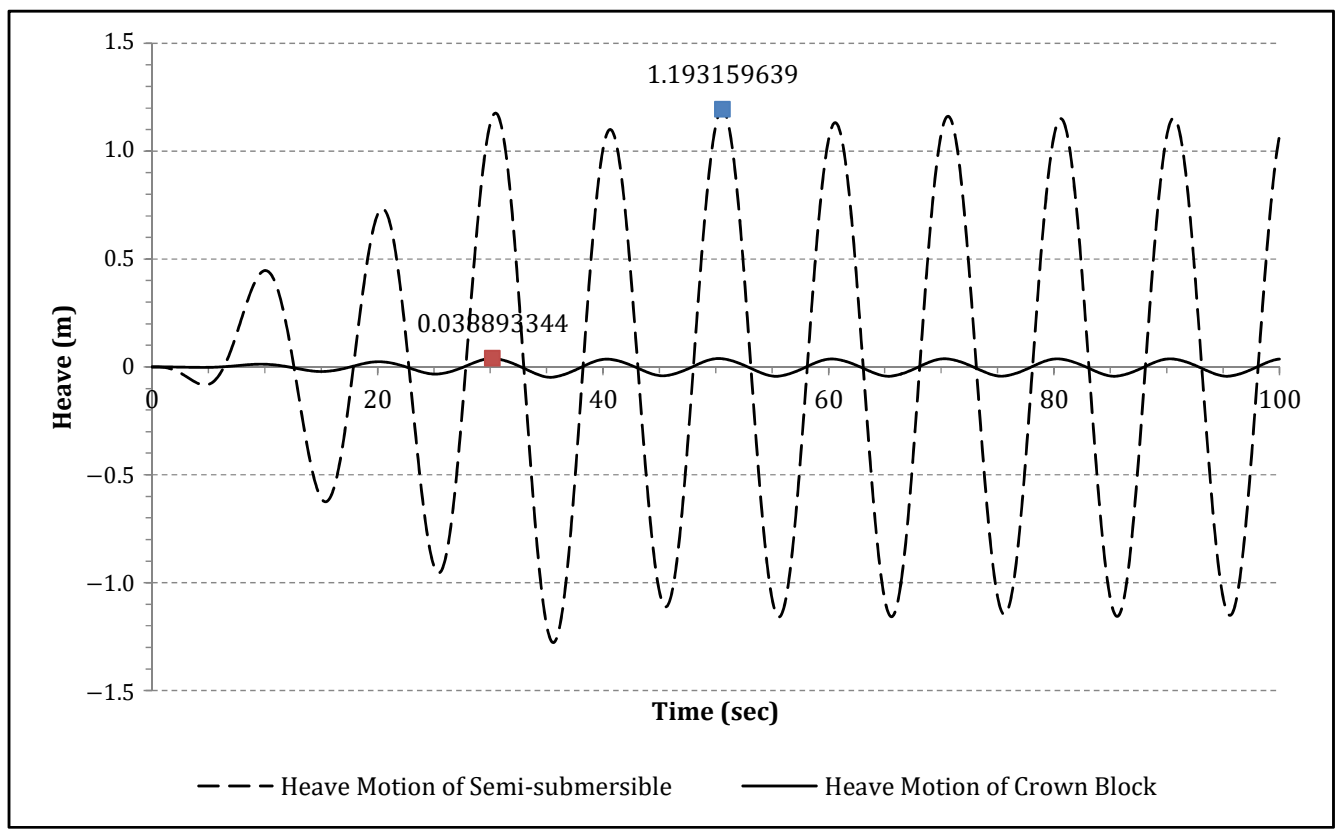

Figure 16. Dynamic response analyses of the semi-submersible and crown block with the heave compensation system for an 8-m wave amplitude.

The efficiency of the DSC is the ratio of the maximum amplitude of the semi-sub to the maximum amplitude of the crown block measured in Figures 17-21. As shown in Figure 22, 1.0 of APV volume was provided initially from the shipyard itself.

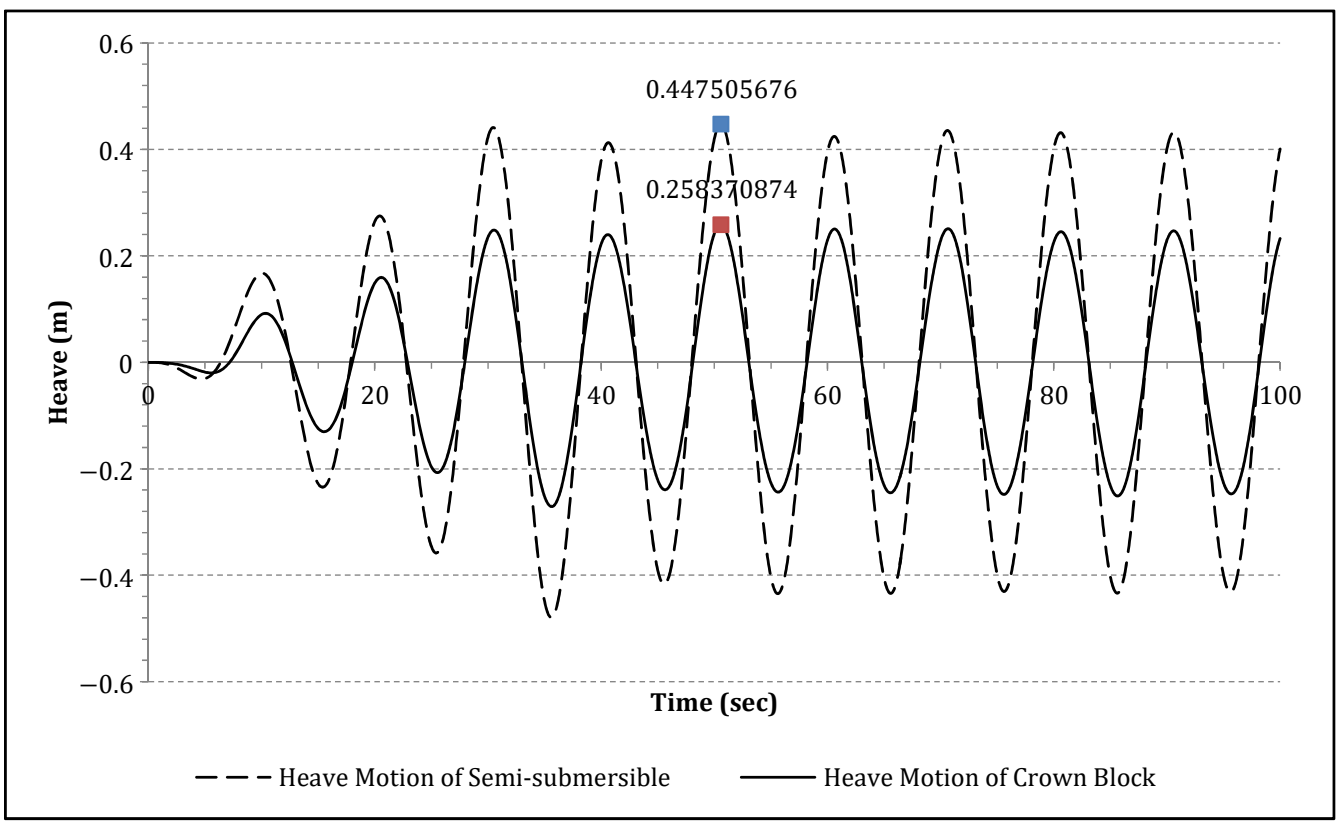

Figure 17. Heave motions of the semi-submersible and crown block for a $16.550 \times 1.0-\mathrm{m}^{3}$ APV. 


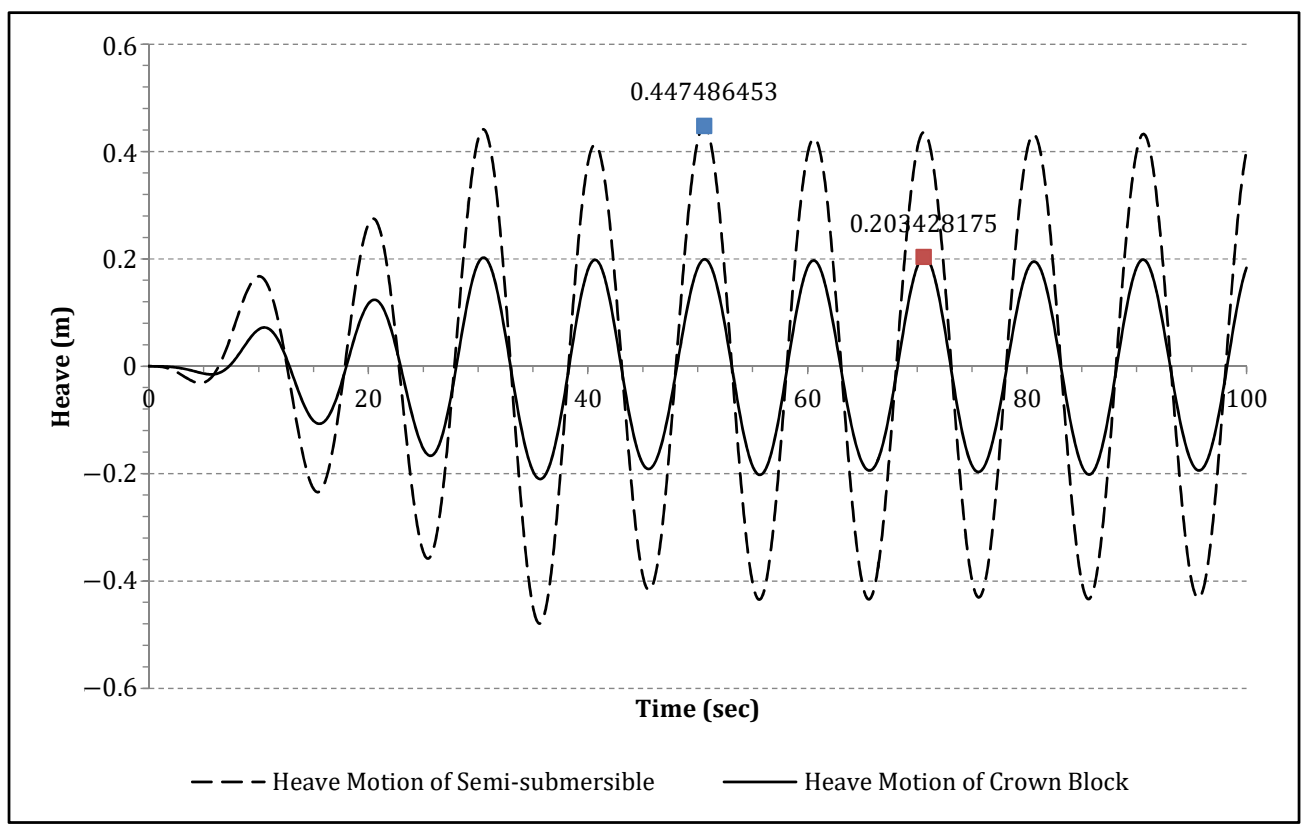

Figure 18. Heave motions of the semi-submersible and crown block for a $16.550 \times 1.2-\mathrm{m}^{3}$ APV.

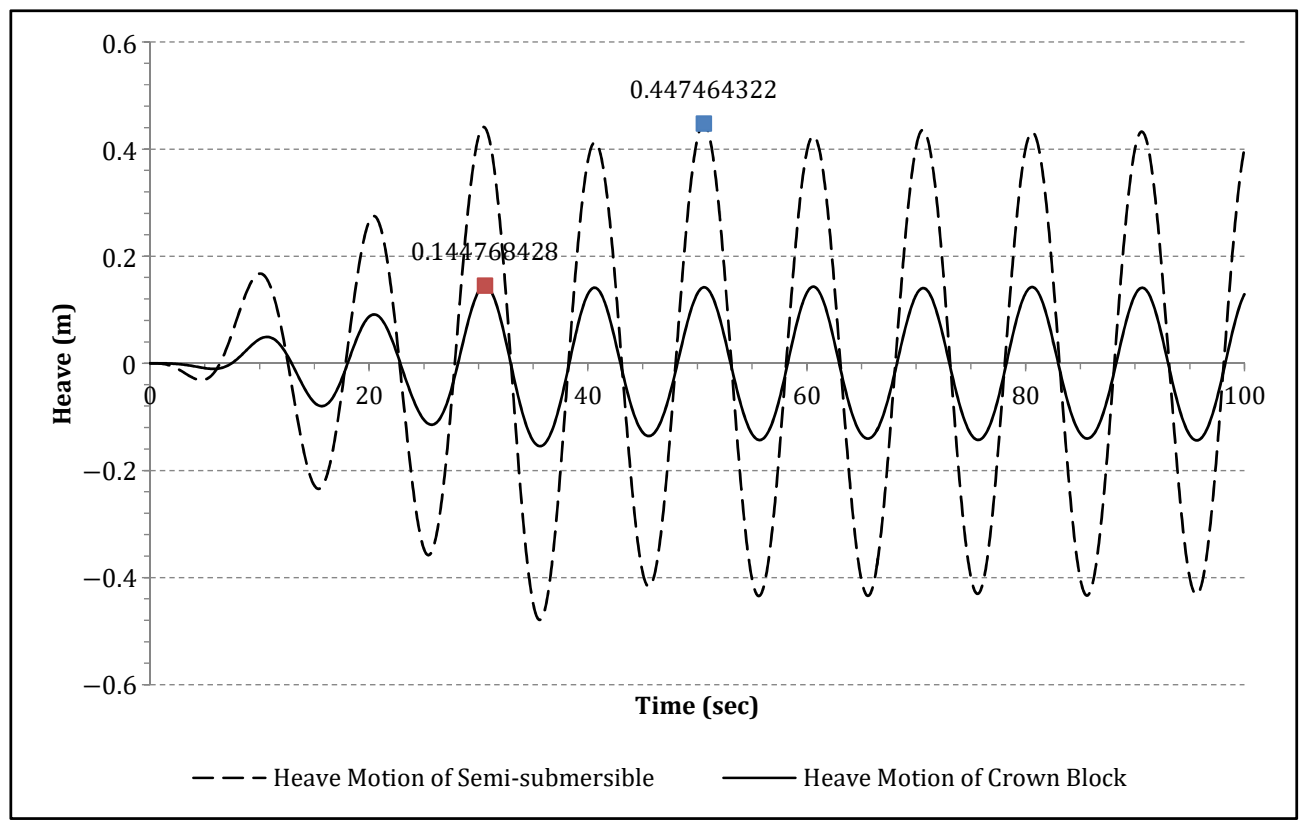

Figure 19. Heave motions of the semi-submersible and crown block for a $16.550 \times 1.4-\mathrm{m}^{3}$ APV. 


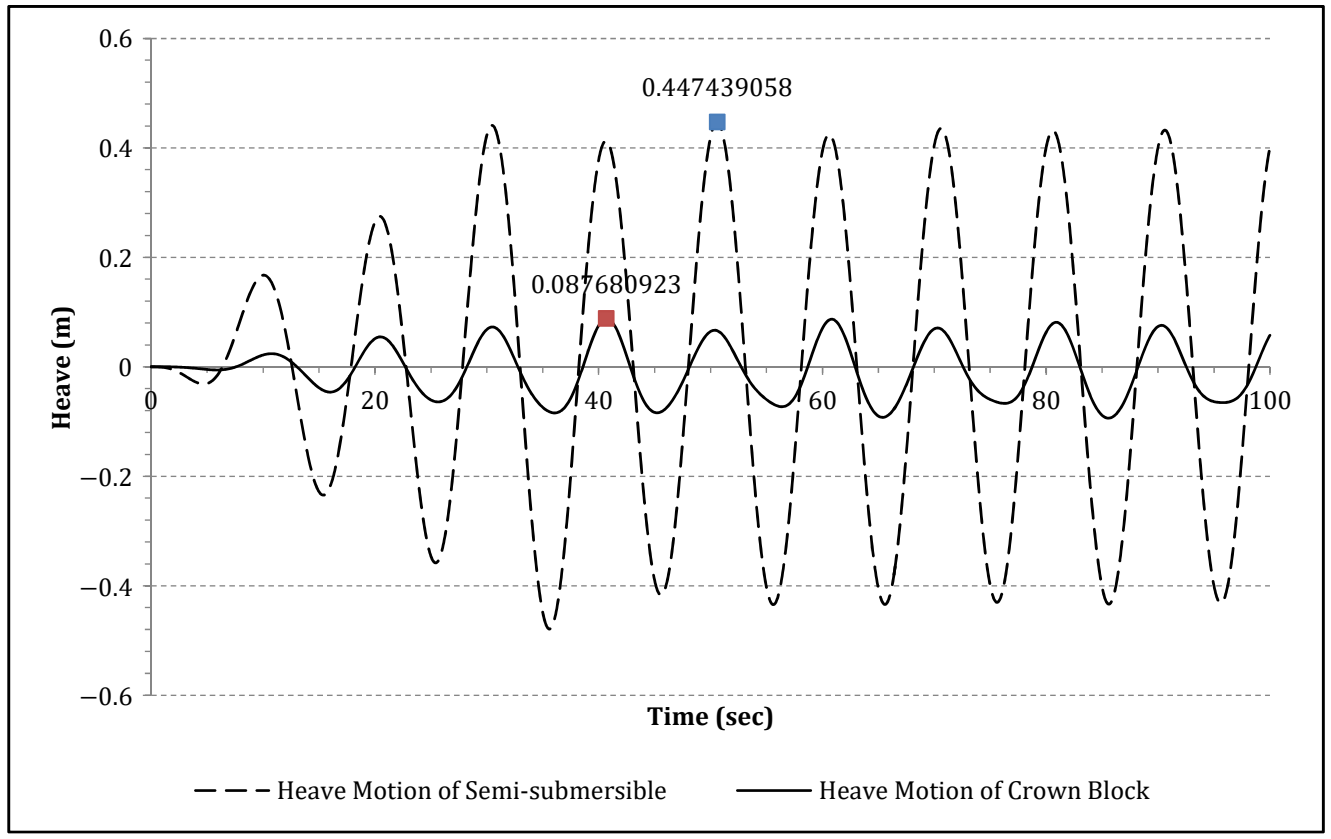

Figure 20. Heave motions of the semi-submersible and crown block for a $16.550 \times 1.6-\mathrm{m}^{3} \mathrm{APV}$.

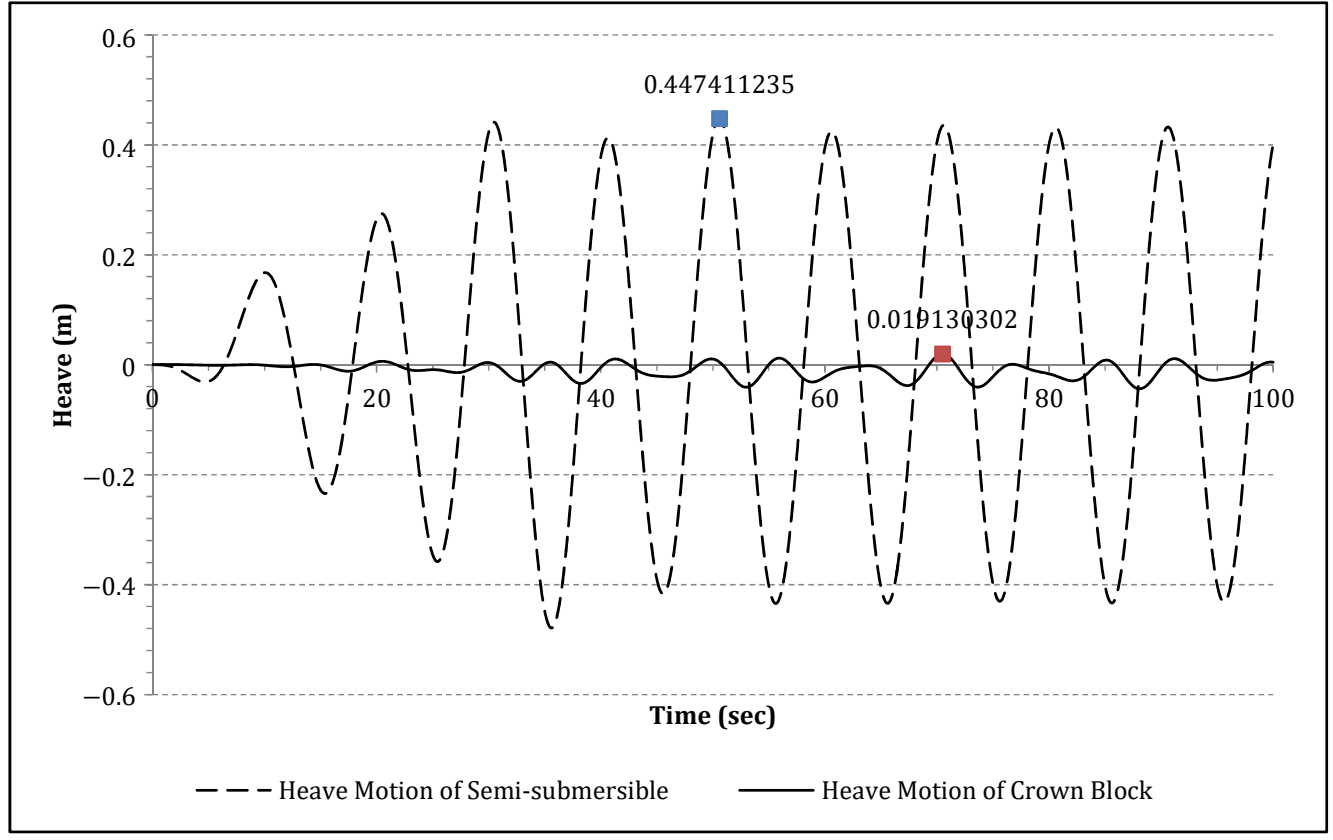

Figure 21. Heave motions of the semi-submersible and crown block for a $16.550 \times 1.8-\mathrm{m}^{3}$ APV.

The larger the APV volume, the higher is the efficiency of the DSC. When the volume reaches $V_{G, 0} \times 1.8 \mathrm{~L}$, the state of the crown block becomes neutral and its restoring force disappears, so it can be considered dangerous. From the above results, we can confirm that the results of the simulation based on multibody dynamics can be utilized for determining the limit and optimum value of the APV volume. 


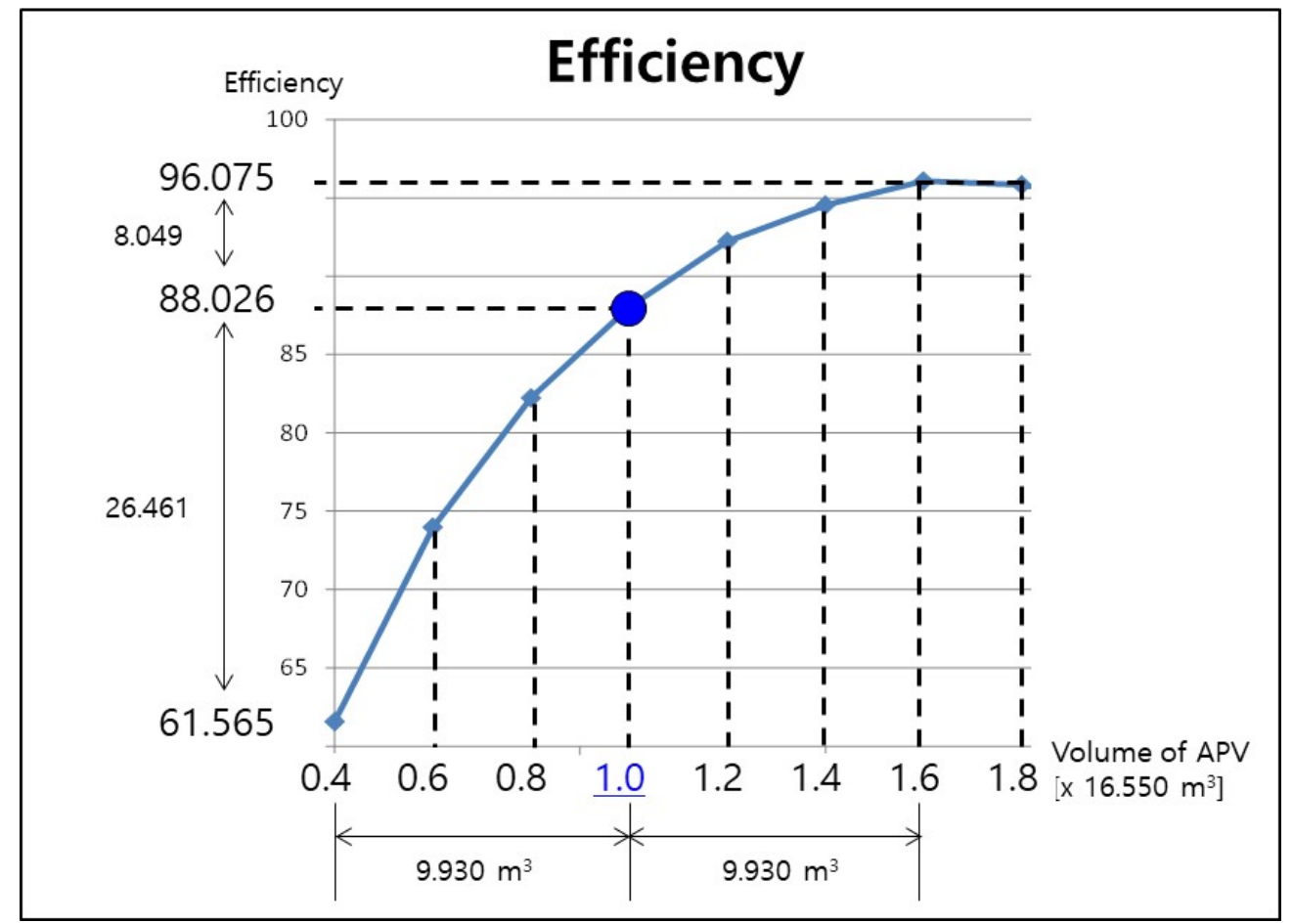

Figure 22. Configuration of the DSC simulation model.

\section{Conclusions}

In this study, dynamic response analysis and control of a simulated hoisting and heave compensation system used on an offshore drilling rig during drilling operations was performed under various wave loads. For modeling the heave compensation system, a multibody dynamics kernel was developed, and pneumatic force was implemented for the DSC. According to the simulation results, the amplitude of the heave motion of the crown block was between 0.0049 and $0.0389 \mathrm{~m}$, and that of the semi-submersible was between 0.1491 and $1.1931 \mathrm{~m}$, which means that the efficiency of the heave compensation system was approximately $96.7 \%$. A parametric study was also conducted using the developed simulation techniques, and the results of the simulation can be utilized for determining the limit and optimum value of the volume of the APV.

Author Contributions: Conceptualization, N.K.; supervision, D.K.; methodology, N.K.; investigation, N.K.; writing, N.K. and D.K. All authors have read and agreed to the published version of the manuscript.

Funding: This study was supported by the National Research Foundation of Korea (NRF) grant funded by the Korea government (MSIT) (No. NRF-2020R1G1A1014243).

Institutional Review Board Statement: Not applicable.

Informed Consent Statement: Not applicable.

Data Availability Statement: Not applicable.

Conflicts of Interest: The authors declare no conflict of interest.

\section{References}

1. Orlandea, N.; Chace, M.; Calahan, D.A. A sparsity-oriented approach to the dynamic analysis and design of mechanical systems-part1\&2. J. Eng. Ind. Trans. ASME 1977, 99, 773-779.

2. Schiehlen, W. Multibody Systems Handbook; Springer: Berlin/Heidelberg, Germany, 1990; pp. 361-402.

3. Smith, R. Open Dynamics Engine v0.5 User Guide. 2006, pp. 15-20. Available online: http:/ / ode.org/ode-latest-userguide.pdf (accessed on 10 August 2021). 
4. FunctionBay, Inc. RecurDyn V7R5 Release Notes. 2011. Available online: https://pdfslide.net/documents/recurdyn-v7r5 -release-notes-v-v-recurdyncatia-read-write-v-v-all-data-number.html (accessed on 10 August 2021).

5. Do, K.; Pan, J. Nonlinear control of an active heave compensation system. Ocean. Eng. 2008, 35, 558-571. [CrossRef]

6. Beutlich, T.; Lien, R. Multidisciplinary simulation of active heave compensators for offshore module handling systems. In Proceedings of the MULTIBODY Dynamics 2009: ECCOMAS Thematic Conference, Warsaw, Poland, 29 June-2 July 2009.

7. Albers, P. Motion Control in Offshore and Dredging; Springer: Berlin/Heidelberg, Germany, 2010.

8. Hatleskog, J.; Dunnign, M. Peer-reviewed technical communication-Passive compensator load variation for deep-water drilling. J. Ocean. Eng. 2007, 32, 3. [CrossRef]

9. Lumeng, H.; Yanting, Z.; Lei, Z.; Meiying, L. Semi-active drilling drawworks heave compensation system. Pet. Explor. Dev. 2013, 40,5 .

10. Bommer, P. A Primer of Oilwell Drilling; The University of Texas at Austin: Austin, UT, USA, 2008.

11. Featherstone, R. Rigid Body Dynamics; Springer: Berlin/Heidelberg, Germany, 2008.

12. Luh, J. On-line computational scheme for mechanical manipulators. J. Dyn. Syst. Meas. Control 1980, 102, 69-76. [CrossRef]

13. Graber, K.; Pollard, E.; Jonasson, B.; Schulte, E. Overview of ocean drilling program engineering tools and hardware. Tech. Notes 2002, 31. Available online: https:/ / www.semanticscholar.org/paper/Overview-of-Ocean-Drilling-Program-Engineering-andGraber-Pollard/701cf277855b5af0e5717159e6060e3b05ffdb33 (accessed on 1 August 2021). [CrossRef]

14. McNary, J.; Person, A.; Ozudogru, Y. A 7500-ton-capacity, shipboard, completely gimbaled and heave-compensated platform. J. Pet. Technol. 1977, 29, 439-448. [CrossRef]

15. Daewoo Shipbuilding \& Marine Engineering (DSME) Co. Ltd. Dynamic Response Analysis and Control of Hoisting System for Drilling Rig in Ocean Environment based on Multibody Dynamics; Technical Research Report; Central Research Institute: Kasauli, India, 2012.

16. Jonggeun, C.; Schubert, J.; Juvkam-wold, H. Analyses and procedures for kick detection in subsea mudlift drilling. SPE Drill. Complet. 2007, 22, 296-303.

17. Jo, A.; Ku, N.; Park, K.; Lee, K. Mathematical modeling and dynamic behavior analysis of drill string compensator for offshore drilling operation. In Proceedings of the Society of Naval Architecture of Korea Fall Conference, Changwon, Korea, 20-25 October 2011. 